\title{
ESTUDO DAS MANIFESTAÇÖES PATOLOGICAS EM INSTITUIÇÖES PÚBLICAS DE ENSINO: O CASO DA UNIVERSIDADE ESTADUAL DO CEARÁ - CAMPUS CIRO GOMES, EM ITAPIPOCA-CE
}

\author{
SOUSA, TÁVIO \\ Estudante \\ Universidade Estadual Vale do Acaraú \\ Ceará; Brasil \\ tavio.engcivil@gmail.com
}

\author{
SALES, JUSCELINO \\ Professor Doutor \\ Universidade Estadual Vale do Acaraú \\ Ceará; Brasil \\ juscelinochaves@hotmail.com
}

\section{RESUMO}

É notório e evidente que a indústria da construçao civil desempenha um papel fundamental para o desenvolvimento de uma nação. Apesar disso é possível se deparar com situações que evidenciam mas práticas construtivas expostas através de patologias nas edificações, principalmente públicas. O presente trabalho tem como objetivo avaliar o grau de manifestações patologicas na intituição de ensino FACEDI, localizada na cidade de Itapipoca-CE. Alem disso pretendeu-se diagnosticar os possíveis agentes causadores de patologias e propor soluções que possam ser implementadas no sentido de sanar ou minimizar os seus efeitos. A metodologia foi composta pelas seguites etapas: investigação da edificação, estudo preliminar, visita de campo, inspeção visual, estudo documental, checklist, registro fotográfico, e identificação da patlogias. Pode-se concluir que a instituição de ensino, objeto da análise desse estudo, possui patologias de diversas naturezas, sendo mais recorrentes as trincas, fissuras e rachaduras nas paredes.

Palavras-chave: patologias, instituições públicas, diagnóstico.

\section{ABSTRACT}

It is notorious and evident that the construction industry plays a key role in the development of a nation. Nevertheless, it is possible to come across situations that show more constructive practices exposed through pathologies, mainly public buildings. This paper aims to evaluate the degree of pathological manifestations in the FACEDI educational institution, located in the city of Itapipoca-CE. In addition, it was intended to diagnose the possible causative agents of pathologies and to propose solutions that can be implemented in order to remedy or minimize their effects. The methodology consisted of the following steps: building investigation, preliminary study, field visit, visual inspection, documentary study, checklist, photographic record, data processing and pathology identification. It can be concluded that the educational institution, object of the analysis of this study, has pathologies of various natures, being more recurrent cracks, cracks and cracks in the walls.

Keywords: pathologies, public institutions, diagnosis.

\section{INTRODUÇÃ̃o}

No decorrer dos anos o ser humano vem reinventando o pensamento no que diz que se refere a construções habitacionais. Percebe-se uma evolução notável quando comparamos estruturas primitivas às atuais. Isso se deve ao fato da aquisição e aperfeiçoamento de técnicas construtivas, além de domínio de elementos naturais. De acordo com Souza e Ripper (1998) o conhecimento acumulado ao longo dos séculos permitiu o desenvolvimento tecnológico da indústria da construção civil, possibilitando o aumento do conhecimento sobre estruturas e materiais construtivos.

Todavia, apesar do aporte de conhecimento na área da construção civil comumente observam-se habitações que não apresentam uma performance satisfatória, gerando transtornos aos que estão direto ou indiretamente ligados às mesmas. Atualmente, com o conceito de desempenho empregado na Engenharia Civil os edifícios começam a ser analisados como um todo, consequentemente, os problemas de desempenho insatisfatório também começam a ser entendidos dentro de um contexto global e não de forma estanque, por defeito (LICHTENSTEIN, 1986). 
O termo patologia das construções é definido por Souza e Ripper (1998) como sendo um novo campo da Engenharia das Construções que se ocupa do estudo das origens, formas de manifestações, consequências e mecanismos de ocorrência de falhas em edificações. Neste sentido, a principal preocupação diz respeito a patologias que afetam a vida útil da edificação. No setor público estes problemas são recorrentes, visto que, muitas empresas contratadas em processos licitatórios não cumprem suas obrigações, entregando obras de má qualidade que futuramente ocasionarão forte impacto no orçamento público, pois há de se provisionar maior quantidade de recursos para a recuperação das instalações deterioradas. Por outro lado, os impactos também são sentidos pela sociedade, que necessita da utilização dos espaços públicos para o atendimento de suas necessidades.

Diante desta problemática percebe-se a necessidade de prever manifestações patológicas em edificações públicas, localizando os pontos críticos de modo a possibilitar um planejamento por parte dos gestores públicos no sentido de sanar tais ocorrências.

O objetivo desse trabalho foi analisar as manifestações patológicas em uma instituição pública de ensino superior, identificando os agentes causadores e as possíveis soluções.

\section{REVISÃO BIBLIOGRÁFICA}

\subsection{Patologias das construções}

É notório que a Engenharia Civil tem conquistado posição de destaque no cenário atual, muito por conta da expansão habitacional que vem promovendo. No entanto, as falhas encontradas em edificações (involuntárias ou por imperícia) dão origem a patologias, que tem culminado no desempenho insatisfatório.

O grande problema das manifestações patológicas se dá pela rápida deterioração das edificações e o surgimento de problemas secundários, acarretando um maior esforço para saná-los. De acordo com Helene (1992) quanto mais cedo for a constatação e correção de uma manifestação patológica, mais duráveis, efetivas, fáceis de executar e baratas serão.

\subsection{Desempenho, vida útil e durabilidade de edificações}

Em virtude das crescentes manifestações patológicas que são acometidas as edificações, na última década muitos órgãos e entidades nacionais e internacionais do setor da construção civil tem promovido um debate técnico acerca de questões relacionadas a desempenho, durabilidade e vida útil, de modo a otimizar o ciclo de vida das construções, em geral.

Os conceitos de durabilidade e vida útil estão intimamente ligados, sendo a vida útil de uma edificação definida pela NBR 15.575 como sendo uma medida temporal de durabilidade, ou seja, o período de tempo em que os elementos que compõem uma edificação se prestam às atividades para as quais foram projetados e construídos, levando-se em consideração a realização dos serviços de manutenção conforme especificado no manual de uso. Entende-se como durabilidade a capacidade de uma estrutura ou de seus componentes de satisfazer, com dada manutenção planejada, os requisitos de desempenho estabelecidos na fase de projeto, por um determinado período de tempo.

O estudo das patologias das construções possibilita à indústria da construção civil a correta atuação na correção de problemas, principalmente aqueles referentes às edificações antigas. Um dos focos dessa abordagem é a tratativa de que a durabilidade das estruturas deve ser priorizada desde a fase de projetos, passando pela escolha de materiais, processos executivos, fiscalização e procedimentos de manutenção e inspeção de estruturas.

Para que a utilização de uma edificação, seja pública ou privada, seja compreendida de forma mais satisfatória, é necessário fazer uma alusão desse setor como de bens de consumo. Conforme Borges (2008), o consumidor (ou usuário) busca adquirir bens de consumo (por exemplo, lâmpadas, automóveis, vestuários e outros) avaliando intuitivamente o desempenho desses produtos. Isso envolve certo conhecimento empírico, de tentativa e erro, no qual se aprende qual produto atende melhor às necessidades de um indivíduo. Dessa perspectiva, normalmente não se compra novamente produtos pouco duráveis ou que não atendem à determinadas expetativas. Contudo, quando se refere a um produto de alto valor agregado, como um imóvel, onde não se tem recursos ou não se deseja adquirir outro por bastante 
tempo, essa situação se inverte. Por estas razões, a questão de desempenho e patologias devem ser tratadas com primazia.

O estudo do desempenho de edificações se mescla com o de patologias, como já discutido. Apesar de um conceito relativamente simples, a sua aplicabilidade de forma integrada, em todas as fases da construção civil, é bastante difícil. Isso ocorre pelo envolvimento de questões técnicas complexas, interesses políticos e econômicos e aspectos subjetivos como as exigências dos usuários.

Ainda, Borges (2008) discute sobre a vida útil de um sistema, entendida como o tempo mínimo esperado em que o desempenho se mantem a níveis contínuos e satisfatórios, sendo apenas realizadas manutenções preventivas. Um conceito semelhante também é tratado pela Norma Brasileira de Desempenho - ABNT NBR 15575 (ABNT, 2013). A Figura 1 mostra essa relação de desempenho relacionada à vida útil de um sistema com manutenção preventiva.

Figura 1 - Desempenho ao longo do tempo.

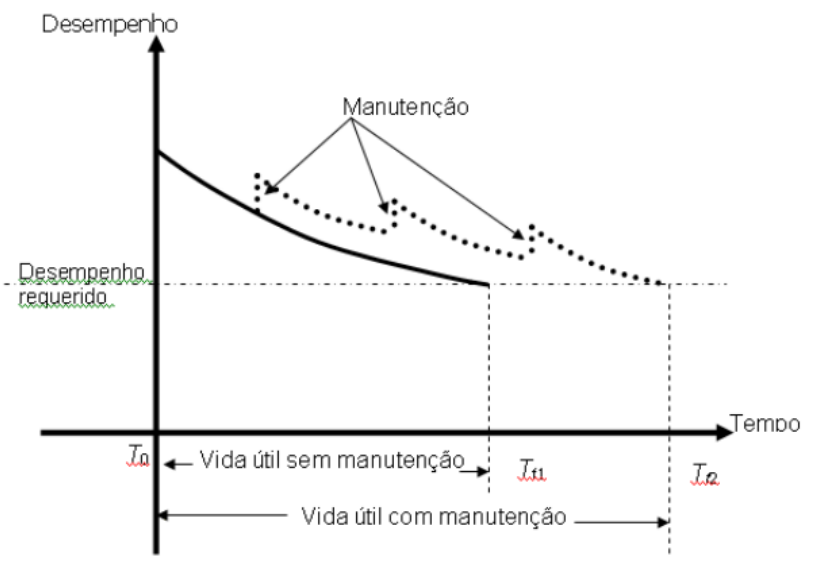

Fonte: ABNT, 2013.

Outro importante aspecto que também se relaciona à questão do tempo, como os outros já citados, é o de garantia. O tempo de garantia envolve um aspecto jurídico que responsabiliza os profissionais envolvidos na execução de uma obra. Para Del Mar (2007), o prazo de garantia observado em uma obra deve ser aquele estabelecido em lei ou contrato, onde o construtor deve responder em lei por vícios construtivos, envolvendo culpa ou não.

No panorama brasileiro, o prazo legal de garantia das construções é de 05 anos, conforme estabelece o artigo 618 do Código Civil Brasileiro (2002). Essa carta legal cita que o empreiteiro de materiais e execução, por esse período, responde pela solidez e segurança do trabalho, inclusive em relação a materiais como solo. É importante ressaltar que para a norma de desempenho, alguns aspectos da estrutura, entretanto, dispõem de garantia variável de 01 ano (para determinados materiais como louças e fechaduras, por exemplo) até 03 anos (para instalações de equipamentos hidráulicos, por exemplo). Essa abordagem de 05 anos é aplicada para a integridade geral da edificação, vedação, estanqueidade, segurança, esquadrias.

É fácil, portanto, relacionar que quanto melhor executado um produto, menos vícios ou defeitos ele poderá apresentar, atendendo satisfatoriamente aos preceitos de durabilidade, desempenho e garantia.

\subsection{Origem das patologias}

Excetuando-se as catástrofes naturais, em que a natureza é o agente preponderante causador, a maioria das patologias tem origem nas falhas relacionadas a alguma atividade desenvolvida durante o processo construtivo de uma edificação. Tal processo pode ser dividido em quatro etapas básicas: concepção, execução e utilização. A fim de que a edificação tenha um desempenho satisfatório deve-se dar a devida importância, de forma equitativa a cada uma dessas etapas construtivas de modo a proporcionar a satisfação do usuário e, principalmente, promover o controle da incidência das manifestações patológicas durante a fase de uso. 
São várias as causas que dão origem a problemas patológicos, logo, deve-se atentar para a necessidade de determinar qual fase tem sido responsável, ao longo dos tempos, pela maior quantidade de erros. Fazendo este diagnóstico é possível realizar alterações na mesma, a fim de evitar a incidências de novos problemas (SOUZA e RIPPER, 1998).

\subsection{Breve histórico de estudos patológicos}

O estudo de patologias é relativamente novo, contudo vem se disseminando na área acadêmica. No que concerne ao ramo, estão in voga estudos não destrutivos que busquem avaliar as condições de desempenho como um todo, bem como aqueles direcionados a áreas de interesse social.

Já Londero, Rachid e Klein (2014) fizeram o levantamento de manifestações patológicas em reservatórios de concreto armado com $500 \mathrm{~m}^{3}$ em Cascavel, Paraná. Após identificação dos reservatórios e reunião de informações históricas com profissionais ligados de alguma forma às estruturas, estabeleceram-se inspeções visuais quantitativas externas, onde foram atribuídas notas de acordo com a gravidade de cada patologia. Foi percebido que fissuras, eflorescências e descolamentos de revestimentos são os problemas mais comuns para esse caso. Embora problemas como esses não representem ameaças diretas a estrutura, afetam os aspectos estéticos e a sensação de segurança percebidos pelos usuários. Os problemas foram relacionados à umidade, aos grandes carregamentos e ações.

Já em Igrejas, Sales e colaboradores (2014) procederam um estudo das patologias na Catedral Metropolitana de Fortaleza. Devido à idade, esses tipos de construções geralmente estão susceptíveis às diversas patologias. Os métodos aplicados pelos autores foram semelhantes a outros supracitados, baseando em investigações bibliográficas, procederam com visitas de campo para a identificação das patologias. Nessa pesquisa, foi percebida a necessidade de manutenções preventivas para a redução da incidência de patologias. A corrosão e lajes e vigas e o destacamento de pintura podem ser relacionados à proximidade da zona marinha e com a presença de pombos cujas fezes tem propriedades químicas reativas com os componentes estruturais e não estruturais.

Em termos de instituições públicas, Vasconcelos, Linhares e Sales (2014), procederam um estudo para analisar a patologias no mercado público de Sobral, CE. É notório que essa instituição não recebeu o aporte de manutenções preventivas que deveria. As patologias foram identificadas e confrontadas com a literatura, buscando suas causas. As principais características identificadas foram manchas, descolamentos, trincas e fissuras e problemas estruturais. Outro ponto identificado foi o fato de o local ser construído em um terreno alagadiço, cuja situação aliada à inexistência de drenagem fez favorecer as patologias de umidade e infiltração, inclusive com brotamento de água.

Martins (2017) também se deteve ao estudo de prédios públicos. A referida pesquisa fez um levantamento das patologias causadas por umidade no campus CIDAO da Universidade Estadual Vale do Acaraú. Seguindo a mesma linha de referência bibliográfica seguida de visitas de campo e registro fotográfico, o autor analisou 09 edificações. Notou-se que os manchamentos e desplacamentos foram os problemas mais comuns. No entanto, também foram identificados mofo, corrosão, eflorescência em musgos em alguns dos prédios estudados. A região mais crítica correspondeu ao bloco da matemática e da física, já a presença mais branda foi contatada no setor de coordenação do curso de matemática. Problemas como esses podem ser consequências de vazamentos da rede hidráulica, má circulação de ar, índice de pluviosidade ou diretamente oriunda do solo, sendo a mitigação adequada a cada especificidade. O autor ainda levantou breve consideração sobre a responsabilidade da administração do local, tendo em vista que interfere diretamente no desempenho e na durabilidade das edificações e, a longo prazo, pode oferecer risco aos usuários.

\section{METODOLOGIA}

Para a abordagem metodológica desse trabalho, foram utilizadas estratégias de diagnóstico. López (2007) destaca que, em engenharia diagnóstica, não é possível listar todos os caminhos para se chegar em um diagnóstico de uma edificação, contudo, é possível estrutura um check-list agregando diferentes informações que indicarão o nível de debilidade de uma estrutura.

Esse diagnóstico foi levantado no Campus Ciro Gomes, da Universidade Estadual do Ceará, na faculdade de Educação (FACEDI). Localizado na região de Itapipoca, CE, esse campus conta com estrutura para abrigar cursos de Química e Biologia, no setor de Educação. O campus é divido em salas de aula, laboratórios e setor administrativo, em três blocos, possui um auditório e a interligação é realizada por rampas e corredores. Totalizando uma área aproximada 
de1.321, $73 \mathrm{~m}^{2}$ de infraestrutura e sendo dividida conforme mostra a Figura 2. O repositório de dados da universidade não permitiu que fossem estudados os projetos arquitetônicos e estruturais, fornecendo apenas acesso a um esboço simples da divisão da unidade.

Figura 2 - Desenho esquemático da FACEDI.

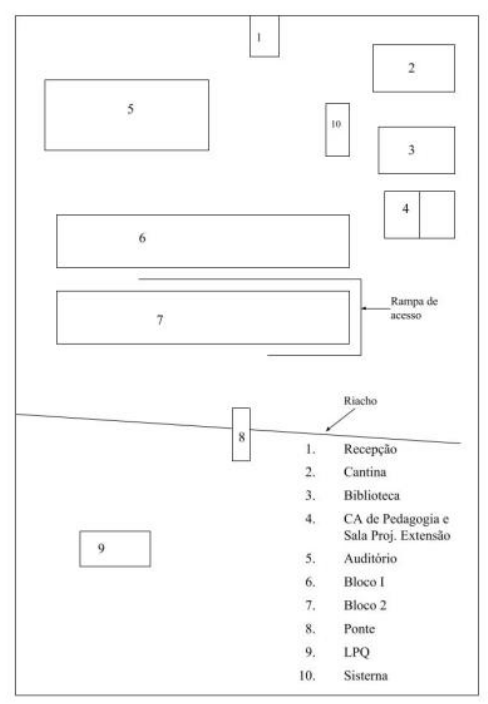

Fonte: Arquivos FACEDI (dados não publicados), 2019.

Em um primeiro momento, foi realizada uma visita de reconhecimento que consistiu de uma investigação preliminar. Essa investigação permitiu que fossem levantadas as características recorrentes das estruturas e estudas as plantas e memoriais de posse da administração. Uma inspeção visual e reconhecimento da estrutura foram feitos. Em um segundo momento, uma nova visita foi realizada de posse de checklist e equipamento fotográfico a fim de que fossem efetivamente registradas as patologias. Após esse exame da estrutura, foi realizada trabalho de gabinete a fim de que os dados fossem processados. A Figura 3 exemplifica o fluxo da investigação.

Figura 3 - Fluxograma da elaboração do estudo.

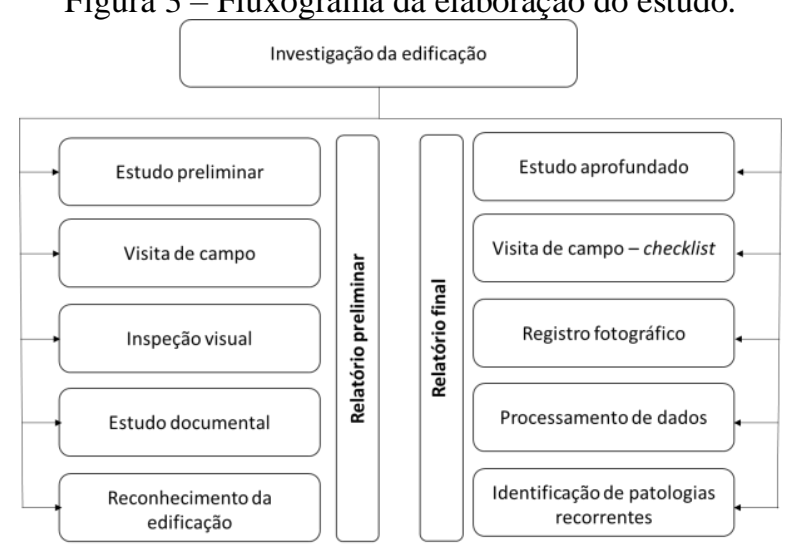

Fonte: Autor, 2019.

Uma análise integrada das patologias foi realizada a partir do levantamento in loco dos problemas da universidade. Para a classificação das patologias, optou-se por seguir pela identificação por tipo (i. e. eflorescência, bolor, desplacamento, fissuras). A partir disso, as patologias foram classificadas qualitativamente, em uma planilha de presença e ausência, o que resultou no diagnóstico das patologias mais frequentes. Essas patologias também foram contabilizadas, por ordem de aparecimento, em cada estrutura.

\section{RESULTADOS E DISCUSSÕES}

\section{1Área de convivência, corredores e rampas}


Para as áreas de convivência, corredores e rampas, as manifestações ocorreram conforme indicado na Figura 4. Nessa avaliação, verificou-se que a manifestação mais recorrente é o bolor (ou mofo) em paredes e elementos estruturais. Seguido disso, também se percebeu um desplacamento recorrente de concreto em vigas e pilares e exposição de elementos elétricos. Em menor grau, também foi possível perceber fissuras, trincas e rachaduras (FTR) em pisos e paredes e também e eflorescências (EFC) causadas por sais.

Figura 4 - Manifestações patológicas em rampas corredores e na área de convivência.

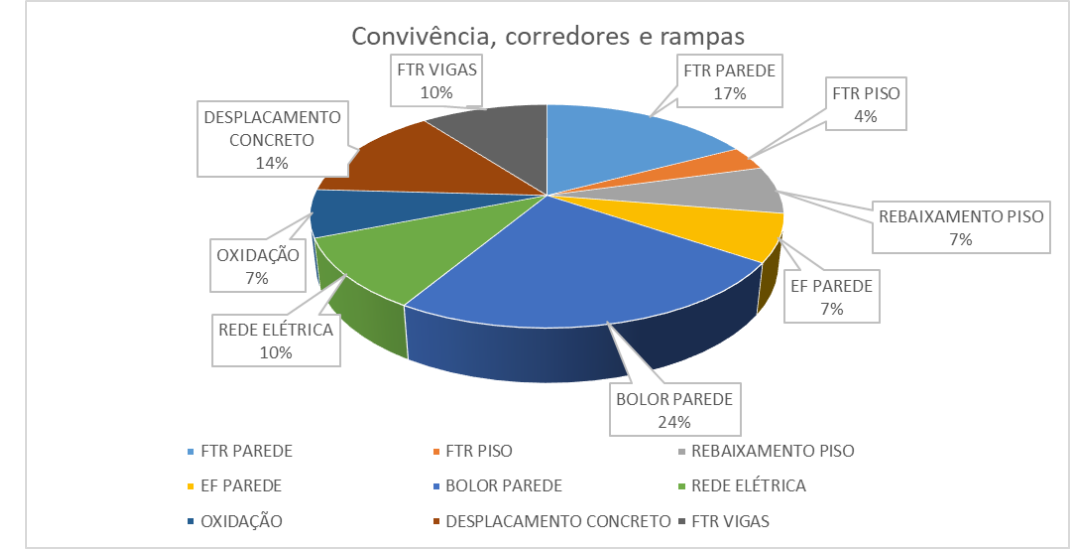

Fonte: Autor, 2019.

Para a ocorrência de bolor, foi verificado que é favorecido por condições de intempéries, estruturas expostas e umidade, seguindo o que é descrito pela literatura (Figura 5 - A). Inclusive, as causas podem estar relacionadas com o aparecimento de outras patologias, como fissurações. O recalque percebido em alguns pontos pode estar relacionado a fundações rasas, construídas sob solo inadequado, sendo também geradores de patologias secundárias. A oxidação prevista no corrimão da rampa se relaciona à falta de manutenção. Fissuras e desplacamento em elementos estruturais podem ao mal adensamento do concreto, provavelmente ocorrido no processo de execução (Figura 5 - B).

Figura 5 - Manifestações patológicas em rampas corredores e na área de convivência.

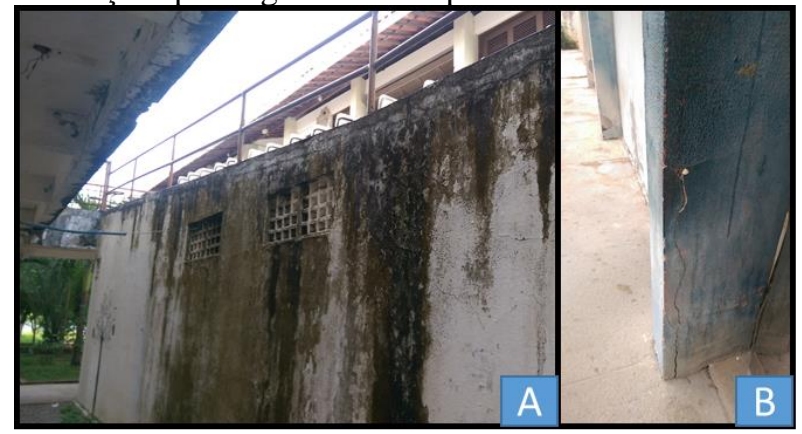

Fonte: Autor, 2019.

\subsection{Auditório}

O maior índice de patologias presente nesse compartimento se relacionou com trincas, fissuras ou rachaduras na alvenaria, decorrentes principalmente de erros de amarração de paredes e de consequências de inexistência de contra vergas (Figura 6). Como no caso anterior, também foi comum perceber bolor decorrente de umidade, podendo ser ocasionado por falhas de impermeabilização no baldrame.

Figura 6 - Manifestações patológicas no auditório. 


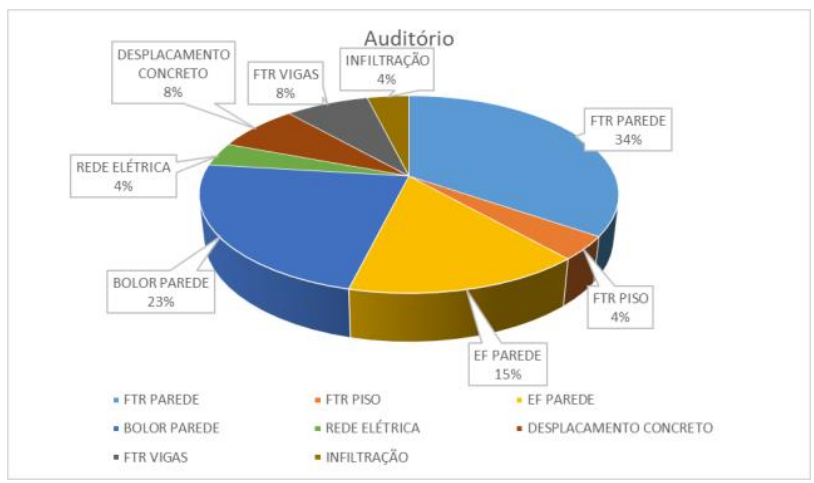

Fonte: Autor, 2019.

A trinca horizontal no encontro de paredes, encontrada nas inspeções de campo, sugere inexistência de amarração, aconselhada pelas boas práticas construtivas. O mofo observado se relaciona com o telhado, tendo em vista sua localização. O que pode estar acontecendo é que devido a um defeito estrutural ou de substituição de telhas, a água é carreada para a específica região e favorece o aparecimento dessa patologia. Essa ideia é reforçada pelo fato de terem sido identificadas infiltrações desde o teto até a parede, com ou sem formação de mofo. Nos desplacamentos de peças de concreto, observou-se a exposição da armadura, podendo indicar algum grau de comprometimento da estrutura. Esse caso é agravado se for considerada a localização do campus, próximo ao mar, que pode potencializar a oxidação dessas armaduras expostas. As rachaduras verificadas no piso, por ser em área externa, pode estar relacionada ao fenômeno de retração e expansão ocasionados pelas diferenças de temperatura. Algumas fissurações e trincas na laje de cobertura e em pilares ou paredes podem estar relacionadas as diferenças de materiais (concreto e argamassa). O episódio não parece estar relacionado à punção, devido as características e orientação da patologia. Nos limites do piso, vigotas de amarração também tem sua armadura exposta, também podendo estar relacionadas à erros de execução. $\mathrm{O}$ aparecimento de fissuras a $45^{\circ}$ nas proximidades de uma janela também indica a ausência de contra vergas. Essas situações aludidas podem ser verificadas na Figura 7.

Figura 7 - Detalhes das manifestações do auditório.

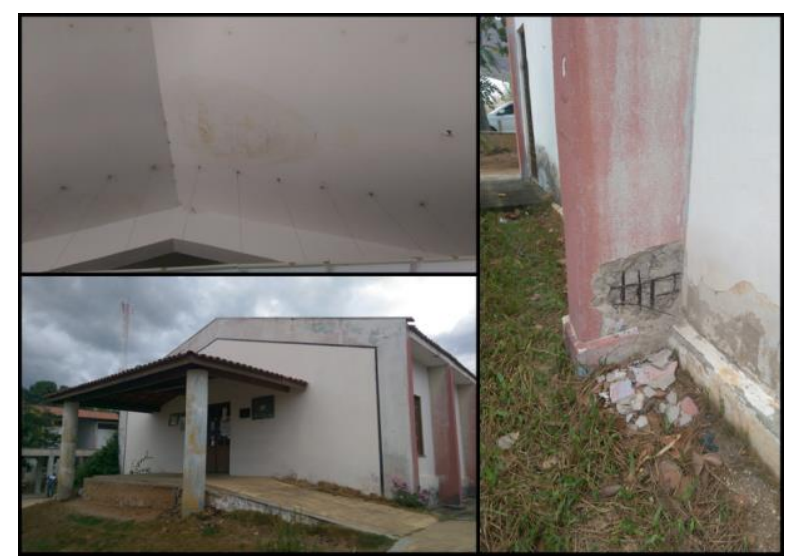

Fonte: Autor, 2019.

\subsection{Bloco 1 - Administração, laboratórios e salas de aula}

A maior incidência de patologias observada para esse caso foi relacionada a problemas com concreto, inclusive com exposição de armaduras e redução da seção útil (Figura 8). Seguido disso, como foi observado nos outros compartimentos, bolor. Esse se destacou também pelo aparecimento de cupim, o que pode indicar a falta de manutenção. Problemas elétricos também foram recorrentes. 
Figura 8 - Manifestações patológicas no Bloco 1.

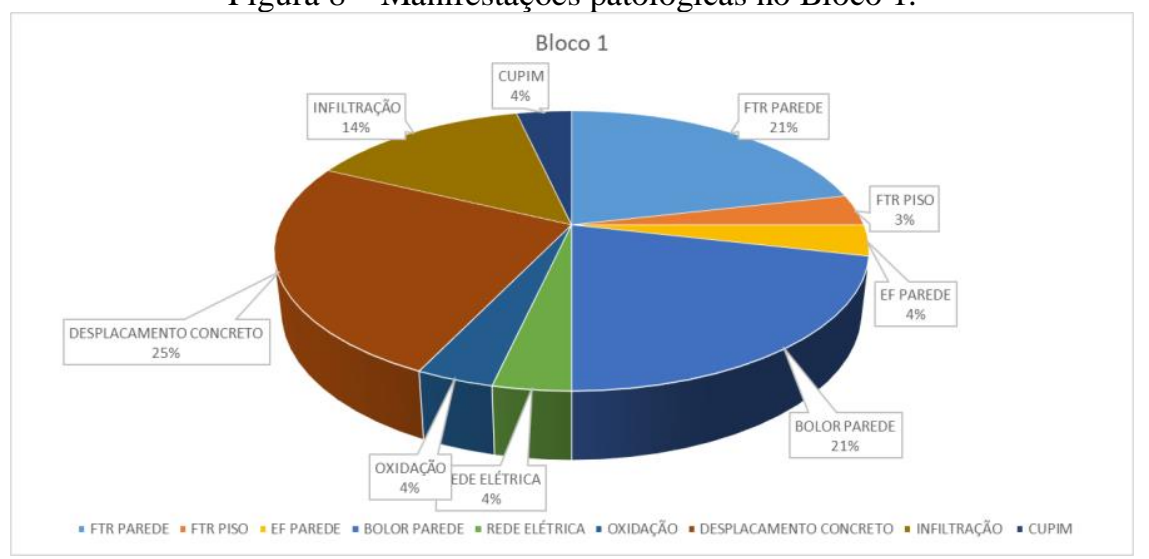

Fonte: Autor, 2019.

O bloco se destacou pela ausência de telhas e presença de cupins na estrutura do telhado. Não houve possibilidade de que se fosse analisado a porção interior do telhado, entretanto o problema foi aparente nos beirais. A falta de telhas também causa mofo nas paredes externas, que são afetadas por eflorescências na porção inferior. Também é visível o desplacamento de peças de concreto nos pilares, sem a exposição da armadura, porém com considerável redução da área útil do pilar. Isso pode ser consequência da qualidade da areia e da resistência projetada (ou não) para o concreto. Contudo, em um dos casos, esse desplacamento foi provoca pela fixação de uma haste de apoio ou suporte para o descanso de bicicletas. A haste pode ter contribuído para causar tensões não previstas em projeto. Devido às intempéries, as fissurações em calçadas se repetem. As esquadrias (portas e janelas) também, com falhas nas paredes adjacentes devido à ausência de contra verga. A laje de cobertura do acesso ao bloco não parece ter o caimento adequado ou um eficiente sistema de drenagem, o que faz com que apareçam infiltrações. A vedação das janelas também encontra-se comprometida, tendo em vista que as pingadeiras não exercem sua função, criando pontos de infiltração e mofo. O problema de infiltração se agrava em alguns pontos da laje de coberta, fazendo com que a armadura fique exposta e se desenvolva mais mofo. $\mathrm{O}$ desplacamento se repete na estrutura de sustentação da rampa, podendo ter sido ocasionado pelas intempéries. Em alguns pontos, estruturas de metal foram utilizadas para dar suporte aos condicionadores de ar, o que fez com que se carreasse água para a parede, favorecendo o aparecimento de mofo. Isso é ilustrado na Figura 9.

Figura 9 - Detalhes das manifestações do bloco 1.

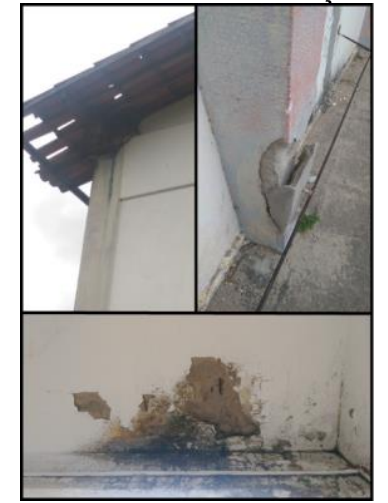

Fonte: Autor, 2019.

\subsection{Bloco 2 - Laboratório de práticas de ensino, salas de aula e banheiros}

Para esse caso, os maiores índices verificados foram de trincas, fissuras e rachaduras pelas mais diversas causas, em paredes (Figura 10). Seguindo isso, também bolor, desplacamento de concreto e problemas na rede hidráulica. Também foram verificados problemas elétricos.

Figura 10 - Manifestações patológicas no bloco 2. 


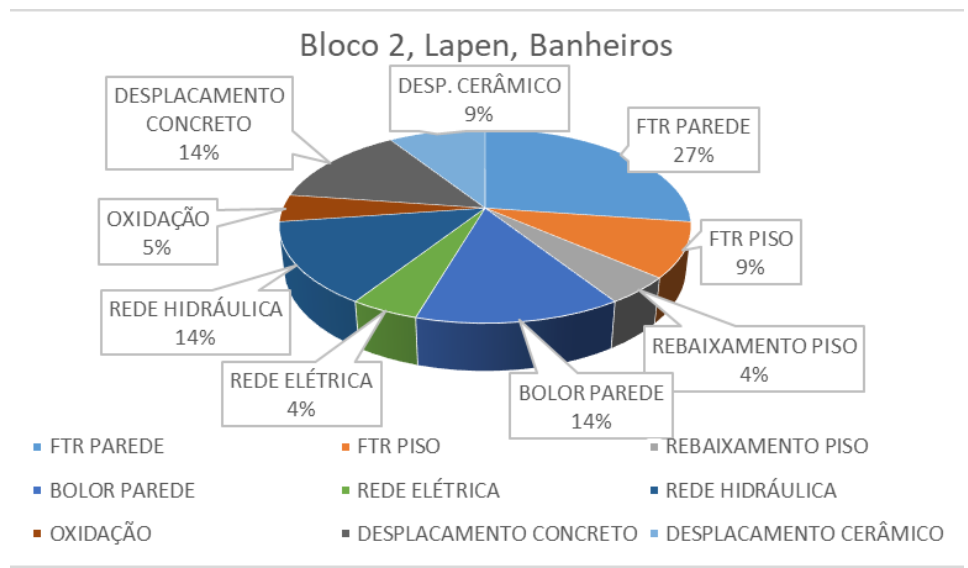

Fonte: Autor, 2019.

Os banheiros desse complexo apresentaram instalações mal acondicionadas, com tubulações expostas, nos lavabos faltavam peças de louças e as terminações de tubulações não contavam com nenhum tipo de proteção. A execução dos banheiros - o que pode ter sido efetuado sem projeto - posicionava ralos para escoamentos de água de forma sucessiva, sem parecer obedecer a um critério específico. A má conservação do revestimento cerâmico também foi evidente, com pontos de mudança de cor, perda da camada esmaltada e desplacamento. As paredes voltaram a apresentar trincas nas adjacências de janelas, o que remete a ausência de contra verga ou de amarração nas paredes ou provenientes de expansão de tijolos. O aparecimento de trincas, rachaduras e fissuras no topo das paredes paralelas à laje podem estar indicando absorção de umidade ou aparecimento de tensões de tração em consequência de movimentações térmicas. Novamente foi percebido o aparecimento de oxidação em corrimãos ao longo do bloco, como também o desplacamento de peças de concreto da estrutura de sustentação das rampas e bolor. Isso pode se relacionar à absorção de umidade. Fissurações no piso, inclusive com quebra e desplacamento cerâmico podem ser relacionados com movimentações de solo ou fundações. No Laboratório de Práticas de Ensino, a forma de eflorescências volta a ser percebida, com prejuízos à pintura do local, o mesmo pode ser percebido nas paredes externas do bloco. O fissuramento vertical também é recorrente, sendo justificado pela mesma hipótese da expansão higroscópica dos tijolos. O piso externo também é afetado por essas movimentações térmicas. Ainda existem adaptações elétricas inadequadas na região externa ao bloco, fazendo com que cabos não estejam protegidos por eletrodutos ou entrem em outros ambientes por janelas. Em alguns pontos, a estrutura do telhado se apoia diretamente nos pilares, o que faz com que essas estruturas sofram esmagamento pelo posicionamento incorreto. As principais características seguem ilustradas na Figura 11.

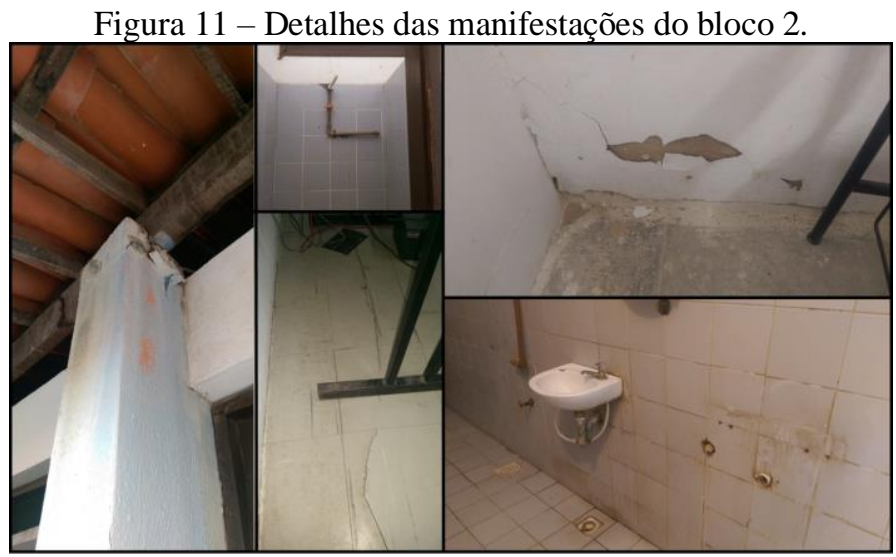

Fonte: Autor, 2019.

\subsection{Bloco 3}

As manifestações mais recorrentes para esse bloco foram derivadas de umidade, com aparecimento de mofo (Figura 12). Seguido disso, fissuras trincas ou rachaduras, infiltrações ou desplacamentos de concreto. Eflorescências também foram recorrentes para esse caso.

Figura 12 - Manifestações patológicas no bloco 3. 


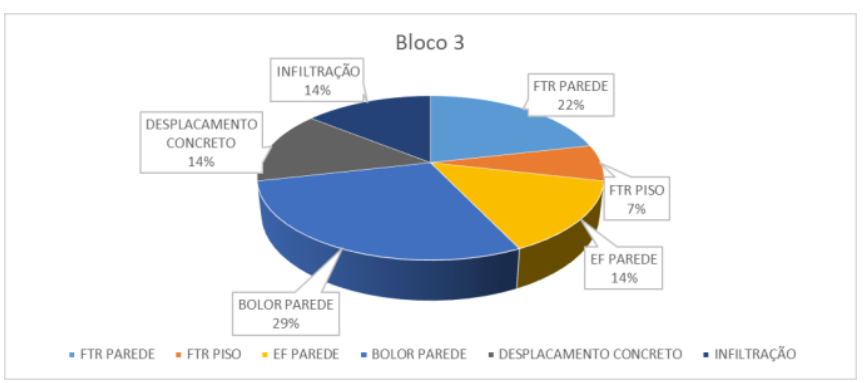

Fonte: Autor, 2019.

No bloco 3 foi percebido que o posicionamento de um condicionador de ar pode ter sido responsável por propagar uma rachadura até o vão da porta. Infiltrações na laje causaram o aparecimento do bolor, que também foi recorrente junto à zona inferior das paredes. Fissuras, trincas e rachaduras também apareceram no piso. Em termos gerais, foi um dos blocos mais conservados visivelmente, durante as visitas de campo.

\subsection{Propostas de intervenção}

De um modo geral, as patologias na Universidade Estadual do Ceará - Campus Ciro Gomes podem ser diagnosticadas conforme a Tabela 1. A maior quantidade de patologias foi percebida em áreas comuns, como corredores, rampas e zonas de convivência. A patologia mais comum foi percebida como sendo trincas, fissuras ou rachaduras, provenientes de umidade, dilatações térmicas ou tensão provocadas por lajes ou equipamentos vinculados à estrutura já existente.

Tabela 1 - Manifestações patológicas na UECE (Campus Ciro Gomes).

\begin{tabular}{|c|c|c|c|c|c|c|}
\hline UECE - CIRO GOMES & $\begin{array}{c}\text { CONVIVÊNCIA, } \\
\text { CORREDORES E RAMPAS }\end{array}$ & AUDITÓRIO & BLOCO 1 & BLOCO2 & BLOCO 3 & TOTAL \\
\hline FTR PAREDE & 5 & 9 & 6 & 6 & 3 & 29 \\
\hline FTR PISO & 1 & 1 & 1 & 2 & 1 & 6 \\
\hline REBAIXAMENTO PISO & 2 & 0 & 0 & 1 & 0 & 3 \\
\hline EF PAREDE & 2 & 4 & 1 & 0 & 2 & 9 \\
\hline BOLOR PAREDE & 7 & 6 & 6 & 3 & 4 & 26 \\
\hline REDE ELÉTRICA & 3 & 1 & 1 & 1 & 0 & 6 \\
\hline REDE HIDRÁULICA & 0 & 0 & 0 & 3 & 0 & 3 \\
\hline OXIDAÇÃO & 2 & 0 & 1 & 1 & 0 & 4 \\
\hline DESPLACAMENTO CONCRETO & 4 & 2 & 7 & 3 & 2 & 18 \\
\hline FTR VIGAS & 3 & 2 & 0 & 0 & 0 & 5 \\
\hline INFILTRAÇÃO & 0 & 1 & 4 & 0 & 2 & 7 \\
\hline CUPIM & 0 & 0 & 1 & 0 & 0 & 1 \\
\hline DESPLACAMENTO CERÂMICO & 0 & 0 & 0 & 2 & 0 & 2 \\
\hline TOTAL & 29 & 26 & 28 & 22 & 14 & 119 \\
\hline
\end{tabular}

Fonte: Autor, 2019.

Atualmente, uma série de intervenções já estão acontecendo devido ao avançado estado de algumas patologias. Segundo a administração, estão previstas substituições de cabos elétricos, tomadas e interruptores, trocas de forros de PVC, intervenções nos banheiros e novo acabamento nas paredes (substituição do reboco e pintura). Durante as visitas, também foi identificado breve intervenção no telhado, o que pode solucionar os problemas de infiltrações nas lajes. Isso resolve parte dos problemas identificados.

A umidade, sem dúvidas, esteve presente em todas as unidades vistoriadas o que faz com que seja necessário rever o sistema de impermeabilização em relação ao solo em determinados pontos. Revisões estruturais também se fazem necessárias em pontos onde há o aparecimento do aço com fim estrutural, como em lajes e pilares, bem como onde há redução da seção útil de pilares. Da mesma forma, é necessário que em pontos onde se verificou o rebaixamento do solo sejam realizados estudos de fundação para adoção da melhor medida a ser tomada.

Os problemas de fissurações de piso externo, em sua maioria de concreto, são inerentes às intempéries de sol e chuva. Já desplacamentos cerâmicos em banheiros podem ser corrigidos com uso de argamassa colante específica. Tubulações danificadas, expostas ou acondicionadas de forra errada podem ser readequadas durante a reforma dos banheiros e áreas exteriores. Para a solução do mofo, além da impermeabilização, tintas com tratamento para o combate a infestações microbiológicas podem ser utilizadas. A fixação de equipamentos como condicionadores de ar e suportes para bicicleta tem de ser reavaliada, podendo ser utilizada uma estrutura com base no solo para que se evite a formação 
de tensões indesejadas. A oxidação em equipamentos de metal, não estruturais, pode ser combatida com a correta limpeza e manutenção periódicas, a fim de que se crie uma camada protetora. Ao passo que as infiltrações podem ser melhoradas com a correta manutenção do telhado, dos sistemas de drenagem e de impermeabilização. Certamente, a presença de cupins indica a falta de manutenção preventiva, tendo em vista o avançado estado da colônia, onde um problema que poderia facilmente ser evitado pode estar comprometendo a estrutura do telhado. Durante a substituição do reboco, também é valido que sejam estudadas as amarrações das paredes, a dilatação dos tijolos e analisas as dilatações das estruturas a fim de se solucionas as questões relativas às fissurações, trincas e rachaduras nas paredes.

\section{CONCLUSÕES}

As patologias se manifestam segundo procedimentos que ser relacionados desde ao projeto até à execução e falta de manutenção. A ausência desses procedimentos acarreta fenômenos físicos, químicos e biológicos e combinações complexas que podem ser de difícil entendimento ou necessitar de investigação detalhada. Não existe edificação "a prova de patologias" mas existem meios que podem ajudar a reduzi-las.

O campus Ciro Gomes, da Universidade Estadual do Ceará, apresentou diversas manifestações: fissuras, trincas e rachaduras, perdas de revestimentos e desplacamento de peças de concreto, exposição de armaduras, mofo, infiltrações, cupins, oxidação, problemas hidráulicos e elétricos. Os problemas mais recorrentes foram fissuras, trincas ou rachaduras em paredes.

Esses problemas, em conjunto, não devem ser negligenciados pois afetam a durabilidade da edificação. Foi visto, pela inspeção, que a falta de manutenção preventiva pode estar diretamente relacionada ao nível de degradação percebido. Para que isso seja mitigado, medidas corretivas foram sugeridas, e, posteriormente, devem ser mantidas por medidas preventivas.

As causas relacionam-se a umidade, dilatações, má execução, utilização de materiais inadequados, adaptações que não obedecem aos projetos, invasores biológicos e outros. Do exposto, destaca-se a importância do campus para formação regional de profissionais na área de ensino, principalmente, sendo necessário que os reparos aqui sugeridos e outros complementares sejam realizados tão logo seja possível para que se zele pelo patrimônio público.

\section{REFERÊNCIAS}

BORGES, C. A. de M. O conceito de desempenho de edificações e a sua importância para o setor da construção civil no Brasil. 2008. 217 f. Dissertação (Mestrado) - Curso de Mestrado em Engenharia, Departamento de Engenharia de Construção Civil, Universidade de São Paulo, São Paulo, 2008. Disponível em: <file://C:/Users/limai/Downloads/Dissertacao_CARLOS_BORGES_Parte_1.pdf>. Acesso em: 26 jan. 2019.

BRASIL. Lei n. 10.406: Código Civil Brasileiro: artigo 618.2002.

DAIHA, K. C. Estudos da agressividade ambiental nas estruturas de concreto armado. Monografia (Graduação). Curso de Engenharia Civil. Universidade Salvador - UNIFACS, 2004.

DEL MAR, C. P. Falhas, responsabilidades e garantias na construção civil. São Paulo: ed. Pini, 2007.366 p.

HELENE, P. R. L. Manual para reparo, reforço e proteção das estruturas de concreto. São Paulo : Pini, 1992.

LANDEIRO, C.; RACHID, L. E. F.; KLEIN, N. S. Levantamento de manifestações patológicas em reservatórios de concreto armado com $500 \mathrm{~m}^{3}$ no município de Cascavel- PR. X Congreso Internacional sobre Patologia y Recuperación de Estruturas, Santiago, 2014.

LIMA, J. M.; PACHA, J. R. S. Patologias das estruturas de concreto armado com ênfase à execução. Centro Tecnológico da Universidade Federal do Pará. Belém, 2000.

MARTINS, D. M. M. Incidência de patologias nas edificações devido a umidade: estudo de caso no Campus Cidao/UVA. 2017. 61 f. TCC (Graduação) - Curso de Engenharia Civil, Centro de Ciências Exatas e Tecnologia, Universidade Estadual Vale do Acaraú, Sobral, 2017. 


\section{CBPAT 2020 \\ CONGRESSO BRASILEIRO DE PATOLOGIA DAS CONSTRUÇÕES \\ DE 15 A 17 DE ABRIL | FORTALEZA - CE \\ ISBN 978-65-86819-05-2

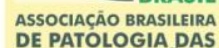 \\ DE PATOLOGIA DAS}

OLIVARI, G. Patologia em edificações. Universidade Anhembi Morumbi, São Paulo, 2003.

SAlES, J. C.; SANTOS, M. W. L. C.; BRANDAO, F. S.; BRAGA, W. A.; LAUREANO, N. S. P. Patologias na Catedral Metropolitana da cidade de Fortaleza no Brasil: Igreja da Sé. X Congreso Internacional sobre Patologia y Recuperación de Estruturas, Santiago, 2014.

SOUZA, Vicente Custódio Moreira de; RIPPER, Tomaz. Patologia, Recuperação e Reforço de Estruturas de Concreto. São Paulo: Pini, 1998.

THOMAZ, E. Tecnologia, gerenciamento e qualidade na construção. Coedição IPT/EPUSP/Editora Pini. São Paulo, 2001.

VASCONCELOS, R. R. R.; LINHARES, P. R. P.; SALES, J. C. Estudo de caso: Análise das Patologias no Mercado Público de Sobral. X Congreso Internacional sobre Patologia y Recuperación de Estruturas, Santiago, 2014. 